Óleo de Grãos de Café Cru: Diterpenos Cafestol e Caveol

Tsukui, A.; Oigman, S. S.; Rezende, C. M.

Rev. Virtual Quim., 2014, 6 (1), 16-33. Data de publicação na Web: 3 de agosto de 2013

http://www.uff.br/rvq

\title{
Oil Green Coffee Beans: Diterpenes Cafestol and Kahweol
}

Abstract: The kaurane diterpenes cafestol and kahweol are significant chemical constituents of the green coffee oil. Studies reveal their potential as antitumor and antioxidant agents; in addition they are recognizably as being hypercholesterolemic. This review focuses on the upgrading of the research conducted on these diterpenes, mainly in biological aspects, extraction techniques and quantification procedures.

Keywords: Coffea arabica L.; coffee oil; cafestol; Kahweol.

\section{Resumo}

Os diterpenos de esqueleto caurano cafestol e caveol são constituintes químicos expressivos no óleo do café cru. Estudos revelam seu potencial antitumoral e antioxidante, além de serem comprovadamente hipercolesterolêmicos. $O$ grão do café é uma commodity agrícola e fonte de cafeína, mas poderia ser melhor aproveitado para a produção de especialidades químicas, visto o seu alto teor em ácidos clorogênicos, fibras e diterpenos. Esta revisão tem como foco a atualização das pesquisas realizadas sobre estes diterpenos, especialmente quanto aos aspectos biológicos, técnicas de extração e quantificação.

Palavras-chave: Coffea arabica L.; óleo de café; cafestol; caveol.

\footnotetext{
* Universidade Federal do Rio de Janeiro, Instituto de Química, Programa de Pós-Graduação em Ciência de Alimentos, Avenida Athos da Silveira Ramos, 149, Cidade Universitária, CEP 21941-909, Rio de Janeiro-RJ, Brasil.

Mannatsukui@ufri.br

DOI: $\underline{10.5935 / 1984-6835.20140003}$
} 


\section{Óleo de Grãos de Café Cru: Diterpenos Cafestol e Caveol Anna Tsukui, ${ }^{\mathrm{a}, *}$ Sílvia S. Oigman, ${ }^{\mathrm{b}}$ Claudia M. Rezende ${ }^{\mathrm{a}, \mathrm{b}}$}

aUniversidade Federal do Rio de Janeiro, Instituto de Química, Programa de Pós-Graduação em Ciência de Alimentos, Avenida Athos da Silveira Ramos, 149, Cidade Universitária, CEP 21941909, Rio de Janeiro-RJ, Brasil.

bUniversidade Federal do Rio de Janeiro, Instituto de Química, Departamento de Química Orgânica, Avenida Athos da Silveira Ramos, 149, Cidade Universitária, CEP 21941-909, Rio de Janeiro-RJ, Brasil.

*annatsukui@yahoo.comb.br

Recebido em 30 de janeiro de 2013. Aceito para publicação em 11 de julho de 2013

\section{Introdução}

2. Os grãos de café cru

3. A composição lipídica do grão de café arábica cru

3.1. Os diterpenos cafestol e caveol

4. Métodos de extração do óleo e dos diterpenos a partir do grão de café cru

4.1. Extração por prensagem

4.2. Extrator Soxhlet

4.3. Incubadora Orbital shaker

4.4. Extração por Fluido Supercrítico

5. Métodos de quantificação dos diterpenos em óleo de café cru

6. Considerações finais

\section{Introdução}

O café, que se propagou do Oriente para o Ocidente, é um marco na história do Brasil. Em 1727 chegou à região norte, trazido pelo Sargento-Mor Francisco de Mello Palheta, por ordem do governador do Maranhão e Grão-Pará, e logo alcançou grande valor comercial. Passou pelo Maranhão, Bahia, Rio de Janeiro, São Paulo, Paraná e Minas Gerais e, em pouco tempo, foi considerado um produto de grande importância para a economia brasileira. A partir de 1820 , no vale do Paraíba, às vésperas da independência do Brasil, o cultivo do café se consolidou. Nos dias de hoje, o plantio de café concentra sua maior produção no estado de Minas Gerais, seguido do Espírito Santo, São Paulo, Paraná, Bahia, Rondônia, entre outros. ${ }^{1}$

Considerado como uma das grandes riquezas brasileiras, o café acelerou o desenvolvimento e a inserção do Brasil no comércio internacional. Além de fomentar o 
surgimento de cidades, construções de ferrovias e portos para o escoamento do grão, trouxe imigrantes para $o$ país $e$ intensificou movimentos culturais. ${ }^{1,2}$ Atualmente, o Brasil é responsável por 30\% da produção mundial, sendo o primeiro produtor de café e o segundo mercado consumidor. ${ }^{1}$ A bebida de café, simbolicamente representada na Figura 1 , cria ambientes sociais, estimula a troca de ideias e a comunicação entre as pessoas. Diversos livros já foram publicados sobre o café, desde sua importância social e econômica, ${ }^{2-4}$ até a composição química e os seus benefícios à saúde. A maior estrela química do café é a cafeína 1, uma xantina com efeito comprovadamente estimulante utilizada em bebidas e medicamentos. Outro grupo de destaque é o do ácido clorogênico 2 e seus derivados di, tri e tetra esterificados, que apresentam elevada atividade antioxidante. Suas estruturas químicas estão apresentadas na Figura $2^{5,6}$

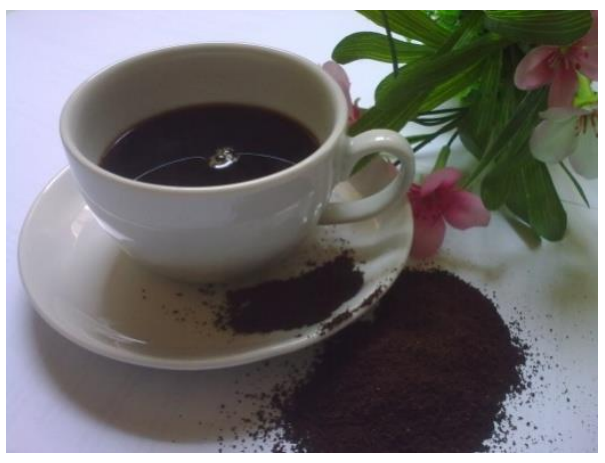

Figura 1. Bebida de café<smiles>Cn1c(=O)c2c(ncn2C)n(C)c1=O</smiles>

1

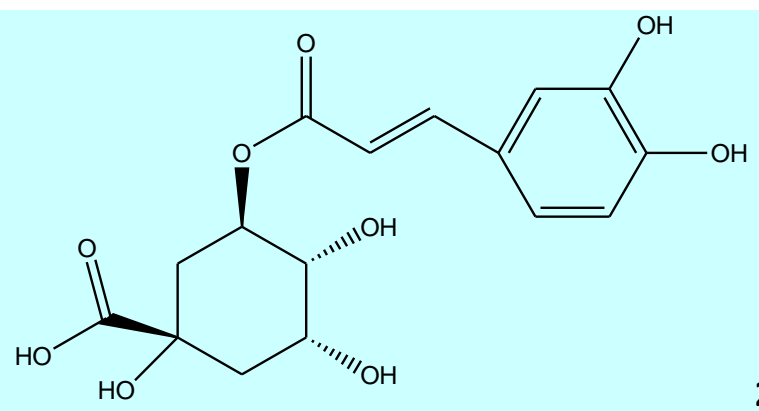

2

Figura 2. Estrutura química da cafeína (1) e do ácido clorogênico (2)

O terceiro grupo de substâncias de destaque presente no grão do café cru é dos lipídeos, tradicionalmente encontrados em qualquer semente e grão vegetal e sendo os constituintes majoritários do óleo fixo. No caso do óleo fixo do café, rico em triglicerídeos e ácidos graxos livres, ocorre, ainda, a presença de diterpenos de esqueleto caurano (3) (Figura 3), tema desta revisão.

Como se pode observar, o grão do café oferece um arsenal de substâncias claramente capazes de acrescentar valor agregado a commodity do café. 0 aproveitamento da biomassa para fins de produção de especialidades químicas, e não apenas para a produção de energia, vai de encontro aos objetivos da Química Verde. Matérias primas renováveis são promissoras para a complementação, ou eventual substituição, do material advindo do processamento do petróleo, do gás natural e do carvão.

Na ponta da cadeia do aproveitamento do café, para além dos alimentos e bebidas, já 
está a indústria de cosméticos, que tem apostado no uso do óleo de café cru como emoliente e hidratante, além da sua

cosmético encontrado no mercado é o extrato de café cru, para fins de redução de peso, associado às propriedades termogênicas da cafeína. ${ }^{8}$

Nesta revisão serão abordados os métodos de obtenção de óleo do grão de capacidade de bloquear os raios solares de UV nocivos à pele humana, aparentemente relacionada aos diterpenos. ${ }^{7}$ Outro produto café cru e sua composição química, especialmente a fração lipídica.

Cabe ressaltar que, de forma geral, considera-se os diterpenos cafestol (4) e caveol (5) (Figura 4) como integrantes da fração lipídica. ${ }^{9}$

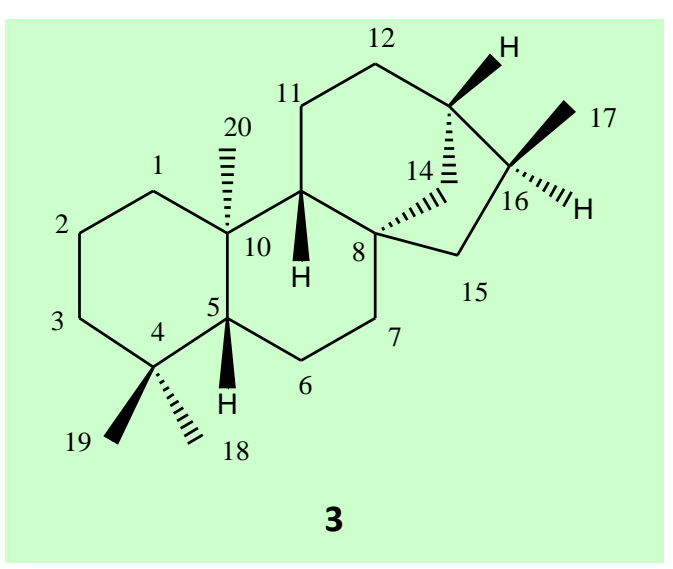

Figura 3. Esqueleto caurano (3)

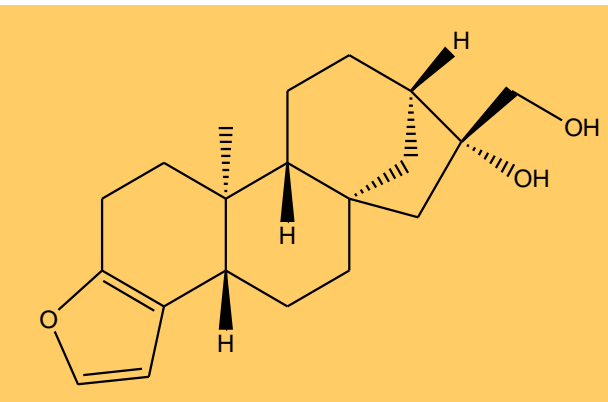

4

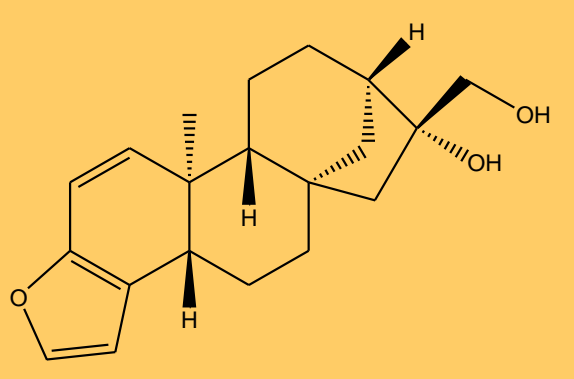

5

Figura 4. Estrutura química do cafestol (4) e caveol (5)

\section{Os grãos de café cru}

A planta do café pertence à família Rubiaceae, gênero Coffea. Dentre as várias espécies de café, aquelas exploradas comercialmente são Coffea arabica Linn (café arábica) e $C$. canephora Pierre ex Froehner (café robusta) (Figura 5$) ; ;^{10}$ as demais espécies cultivadas representam um acervo para estudos de melhoramento genético das comerciais. ${ }^{11} \mathrm{O}$ café arábica é responsável por cerca de $70 \%$ do mercado mundial de café. $^{12}$

A composição química do endosperma do grão de café arábica cru é constituída por 
água, proteínas, óleos e lipídeos, açúcares, dextrina, pentosanas, celulose, cafeína, ácidos diversos e componentes minoritários. Os lipídeos estão presentes em forma de gotas esféricas em cada célula do endosperma. ${ }^{13}$ Como para qualquer vegetal de aproveitamento agronômico, o estudo da anatomia do grão e sua composição química se tornam relevantes em função das alterações morfológicas, fisiológicas, bioquímicas e funcionais que ocorrem durante os estágios de desenvolvimento e maturação do grão, aspectos que impactam na qualidade do produto final. ${ }^{14}$

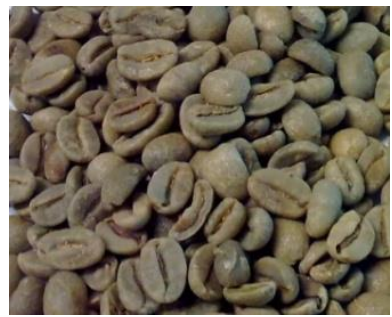

Figura 5. Grãos de café cru arábica (esquerda) e robusta (direita)
Estas substâncias são precursoras do aroma do café torrado, e sofrem transformações químicas diversas com forte dependência do grau de torra. Os ácidos clorogênicos, por exemplo, se mantêm parcialmente intactos em torras mais suaves, mas produzem invariavelmente alguns dos compostos voláteis responsáveis pelo aroma característico do café torrado, como: 2- metóxi-4-vinilfenol, 2- metóxi-4-etilfenol e guaiacóis. $^{15-17}$

$\mathrm{Na}$ Tabela 1 está apresentada a composição química média do grão de café cru, já que os teores variam com as espécies botânicas, as condições de cultivo, o clima da região de plantio e processo de secagem. ${ }^{9,17-}$ 19

Tabela 1. Composição química do grão de café arábica cru ${ }^{18}$

\begin{tabular}{|c|c|c|}
\hline Componente & Café arábica (\%) & Café robusta (\%) \\
\hline Cafeína & $0,8-1,4$ & $1,7-4,0$ \\
\hline Trigonelina & $0,6-1,2$ & $0,3-0,9$ \\
\hline Minerais & \multicolumn{2}{|c|}{$3-5,4$} \\
\hline Ácidos clorogênicos totais & $6,7-9,2$ & $7,1-12,1$ \\
\hline Ácidos alifáticos não voláteis & $2-2,9$ & $1,3-2,2$ \\
\hline Ácidos voláteis & \multicolumn{2}{|c|}{0,1} \\
\hline Carbo-hidratos solúveis & $9-12,5$ & $6,0-11,5$ \\
\hline Polissacarídeos insolúveis & $46-53$ & $34-44$ \\
\hline Lignina & \multicolumn{2}{|c|}{$1-3$} \\
\hline Proteínas & \multicolumn{2}{|c|}{$8,5-12$} \\
\hline Aminoácidos livres & \multicolumn{2}{|c|}{$0,2-0,8$} \\
\hline Ceras & \multicolumn{2}{|c|}{$0,2-0,3$} \\
\hline óleos & \multicolumn{2}{|c|}{$7,7-17,7$} \\
\hline
\end{tabular}




\section{A composição lipídica do grão de café arábica cru}

Os lipídeos vegetais, com destaque para os triacilglicerídeos, estão presentes em muitos setores industriais com diversas aplicações, como na indústria de alimentos em óleos, margarinas e laticínios; na indústria química em tintas, vernizes e lubrificantes automotores; na indústria de cosméticos e farmacêutica como insumos para a produção de cremes, emulsões e pomadas e também como combustível alternativo. ${ }^{20,21}$

Os lipídeos possuem funções metabólicas importantes para o crescimento e sobrevivência da planta. ${ }^{20,22}$ Eles estão presentes nas membranas celulares, em células e tecidos especializados, em maior teor nas sementes e raramente ocorrem expressivamente nas folhas, estames e raízes. Em angiospermas, os lipídeos estão concentrados no endosperma ou cotilédone, já nas gimnospermas estão armazenadas no gametófito feminino. ${ }^{22}$

Na planta do cafeeiro, uma angiosperma, os lipídeos estão armazenados em compartimentos especializados no citosol, onde há centenas de milhares em cada célula de armazenamento, conhecidos como esferossomos ou oleossomos. Os oleossomos são formados a partir de duas fontes: o retículo endoplasmático e os plastídios. 0 retículo endoplasmático é um envelope nuclear envolvido na biossíntese, processamento e secreção de lipídeos, proteínas e polissacarídeos na membrana celular. Os plastídios constituem uma família de organelas circundadas por dupla membrana, característicos das células de plantas. Os lipídeos se acumulam entre as duas camadas de fosfolipídeos e glicolipídeos presentes na membrana externa do envelope de plastídios ou na membrana do retículo endoplasmático. Esse acúmulo provoca a separação de bicamada lipídica em duas metades, formando o oleossomo ou esferossomo. ${ }^{22}$

De modo geral, os constituintes lipídicos do grão de café cru são semelhantes aos dos grãos de muitos vegetais: presença de triacilgliceróis, fosfolipídeos, esteróis, tocoferóis e os constituintes da cera que recobrem o grão. Mas, diferente dos óleos vegetais, o óleo de café cru apresenta alto nível de material insaponificável (12\%), rico nos diterpenos cauranos cafestol (4) e caveol (5). ${ }^{9,23-25}$

No óleo fixo dos grãos de café cru, os triacilglicerídeos estão presentes em maior teor, seguido dos ésteres diterpênicos, dos diterpenos livres, ésteres de esteróis, esteróis, tocoferóis e fosfatos (Tabela 2).

Tabela 2. Composição lipídica do óleo obtido do grão de café arábica cru (matéria seca) $)^{9}$

\begin{tabular}{|cc|}
\hline Componentes & Teor (\%) \\
\hline Triacilglicerídeos & 75,2 \\
Ésteres diterpênicos e ácidos graxos & 18,5 \\
Diterpenos livres & 0,4 \\
Ésteres de esteroides e ácidos graxos & 3,2 \\
Esteróis & 2,2 \\
\hline Tocoferóis & $0,04-0,06$ \\
Fosfatídios & $0,1-0,5$ \\
\hline Outros & 1,0 \\
\hline
\end{tabular}


Os ácidos graxos ocorrem na natureza na forma livre e esterificada, majoritariamente formando triacilglicerídeos. ${ }^{26}$ No óleo do grão de café arábica cru estão presentes aproximadamente os seguintes ácidos graxos: ácido mirístico (2-3\%), ácido palmítico (30\%), ácido esteárico (4-5\%), ácido oleico
(14\%), ácido linoleico (44\%), ácido linolênico (1-2\%) e o ácido araquídico (1-2\%). ${ }^{25,27} \mathrm{Em}$ torno de $20 \%$ dos ácidos graxos estão esterificados com diterpenos (6) (Figura 6) e uma pequena parte é encontrada nos ésteres de esteróis. ${ }^{9}$

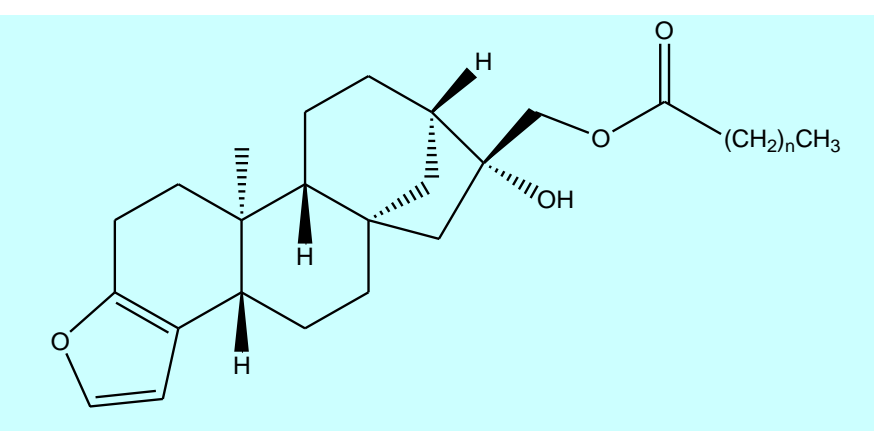

onde $n=14,16,17,18,18: 1,18: 2,18: 3,20,21,22,23$ ou 24 .

6

Figura 6. Cafestol esterificado com ácido graxo (6)

\subsection{Os diterpenos cafestol e caveol}

Os grãos de café arábica ( $C$. arabica) apresentam majoritariamente cafestol (4) e caveol (5) na fração lipídica, enquanto $C$. canephora (café robusta) apresenta mais cafestol (4) e teores mínimos ou inexistência de caveol (5), e tem como marcador da espécie o 16-O-metilcafestol (7) (Figura 7), identificado em 1987. ${ }^{9}$ O teor de cafestol (5), usualmente determinado após saponificação ou metanólise (Figuras $8 a$ e $b$, respectivamente), ${ }^{28}$ está entre $2,7-6,7 \mathrm{~g} / \mathrm{kg}$ em cafés arábica e entre 1,5-3,7 $\mathrm{g} / \mathrm{kg}$ em cafés robusta, ${ }^{29,30,31}$ enquanto o de caveol (5) está entre 1,1-3,5 g/kg em cafés arábica e em concentração inferior a $0,1 \mathrm{~g} / \mathrm{kg}$ em robusta. $\mathrm{O}$ teor de 16-O-metilcafestol em café robusta varia entre 0,6 a $1,8 \mu \mathrm{g} / \mathrm{kg}^{32}$

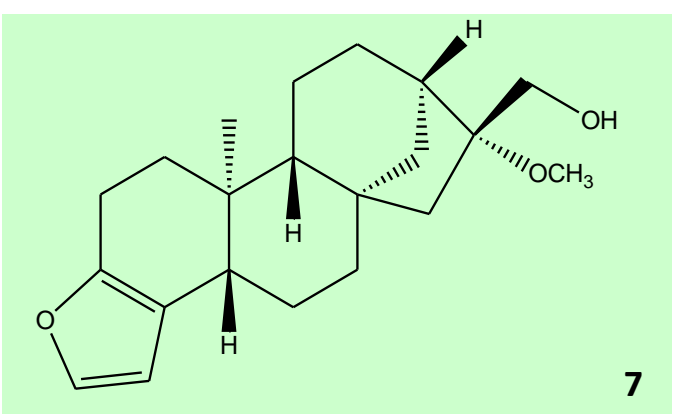

Figura 7. Estrutura química do 16-O-metilcafestol (7) 


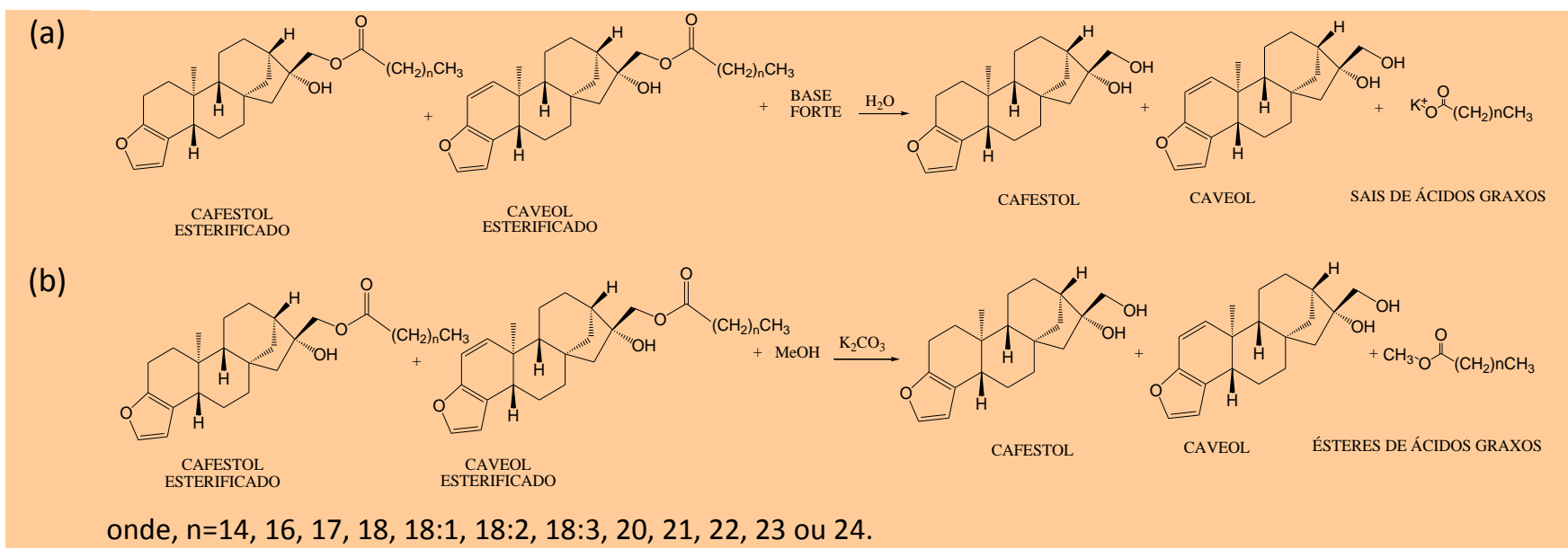

Figura 8. Reação de saponificação (a) e metanólise (b)

O caveol (5) foi parcialmente descrito em 1932 ("kahweol" ou café, em árabe), e caracterizado como sendo sensível ao oxigênio, à luz, ao aquecimento e especialmente aos ácidos minerais. Após purificação, o caveol é instável e rapidamente torna-se amarelado, observando-se uma rápida alteração de seu ponto de fusão, da solubilidade e atividade óptica. ${ }^{33}$

Em 1938, foi isolado o "cafesterol", que inicialmente se acreditou ser um esterol, com fórmula molecular $\mathrm{C}_{20} \mathrm{H}_{28} \mathrm{O}_{3}$ e que, posteriormente, em 1943, veio a ser chamado de cafestol (4). ${ }^{34,35} \mathrm{Em} \mathrm{1957,} \mathrm{o} \mathrm{anel}$ furano foi confirmado através de ressonância magnética nuclear de hidrogênio e sua configuração absoluta foi definida em $1960 . .^{36,37}$

Outros cauranos foram descritos no café e correlacionados ao processo de torra do grão cru, originários principalmente dos diterpenos livres, sendo eles: dehidrocafestol (8), de-hidrocaveol (9) (Figura 9), cafestal (10), caveal (11) (Figura 10), isocaveol (12) e de-hidroisocaveol (13) (Figura 11). ${ }^{9,38,39}$
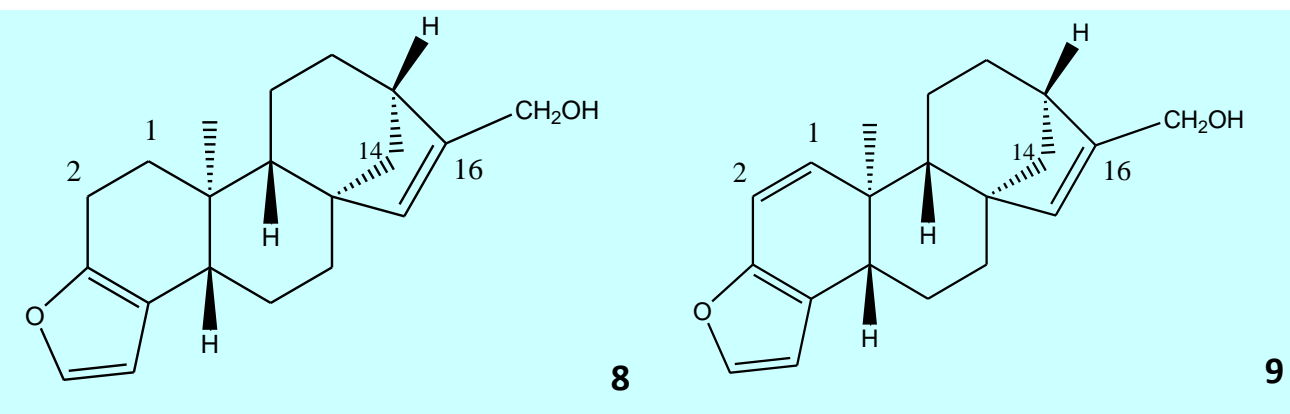

Figura 9. Estrutura química do de-hidrocafestol (8) e de-hidrocaveol (9) 


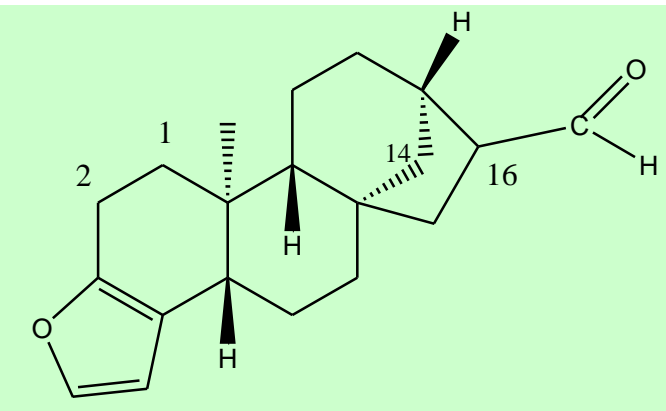

10

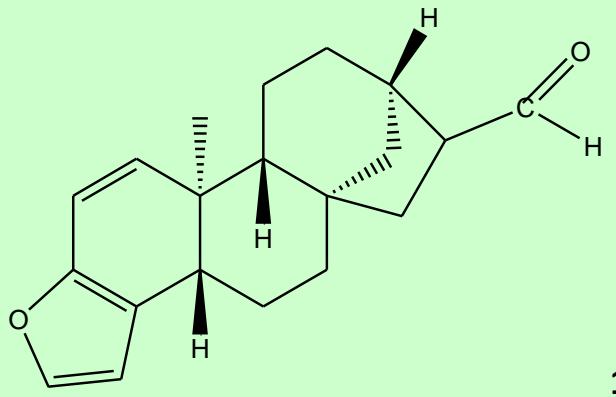

11

Figura 10. Estrutura química cafestal (10) e caveal (11)
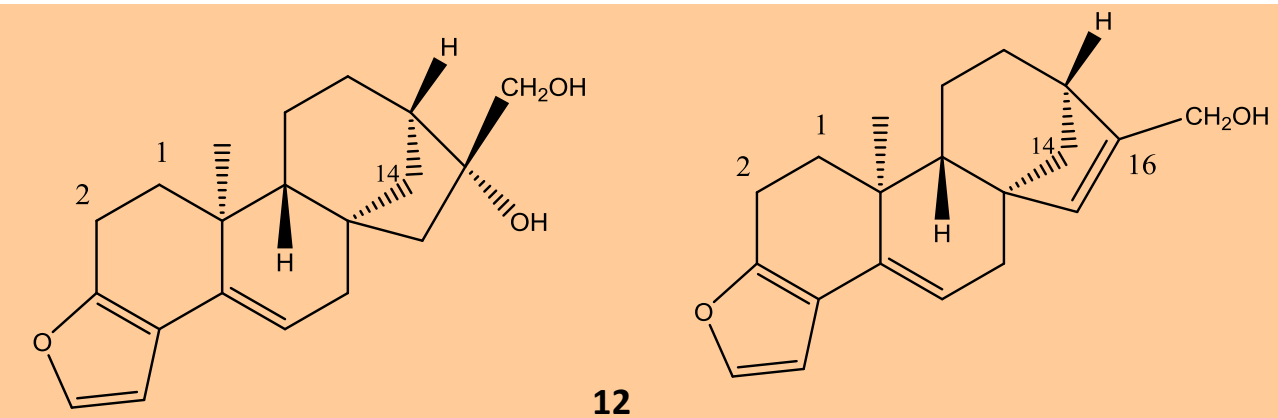

12

Figura 11. Estrutura química do isocaveol (12) e de-hidroisocaveol (13)

$\mathrm{Na}$ forma não esterificada (livre), os diterpenos estão presentes nos grãos de café cru em concentrações inferiores a $0,2 \mathrm{~g} / \mathrm{kg}$ de grão. ${ }^{32}$

Os principais ácidos graxos presentes nos ésteres diterpênicos são: ácido palmítico (4054\%), ácido linoleico (19-30\%), esteárico (8$11 \%)$, oleico $(8,2-15 \%)$ e araquídico (4,5-6\%). Os teores dos diterpenos esterificados com ácido mirístico, linolênico, eicosenoico e behênico são inferiores a $2 \%{ }^{25}$ Outros diterpenos esterificados já encontrados foram gadoleiato, margarato, heneicosanoato e tricosanoato de caveol. ${ }^{9,27,32}$

O grão de café cru é sensível às condições de estocagem. $O$ ambiente frio e seco provoca um leve aumento no teor de cafestol livre. Entre $25^{\circ} \mathrm{C}$ e $40^{\circ} \mathrm{C}$, o aumento chega a até $16 \%$ e os maiores valores são observados aos 12 meses, após os quais se pronuncia a degradação dos diterpenos. As alterações foram relacionadas à atividade das lipases, onde o aumento da umidade do grão e temperaturas mais altas favorece a hidrólise de ésteres de ácidos graxos, a decomposição dos diterpenos e provocam efeito negativo na qualidade sensorial do grão. ${ }^{9}$

\subsubsection{Funcionalidades do cafestol e caveol}

Em 1982 foi relatado que os palmitatos de cafestol e de caveol aumentavam a atividade da glutationa $S$-transferase (GST), um grupo de enzimas multifuncionais capaz de atuar na defesa das células contra o estresse oxidativo e frente às substâncias estranhas ao organismo, conhecidas como xenobióticos. Nos experimentos que buscavam a correlação entre GST e a resposta frente à redução de células carcinogênicas, foi observado que o palmitato de caveol apresentou maior indução da atividade da GST comparado com o palmitato de cafestol. ${ }^{40}$

Em 1988, foram realizados testes frente à inibição de câncer de boca em hamsters Sírio feminino, divididos em dois grupos. O grupo I 
recebeu alimentação com ração normal e o grupo II com $20 \%$ de adição de grão de café verde na ração. Todos os animais foram expostos a $0,5 \%$ de 7,12dimetilbenz[a]antraceno (DMBA), produzindo câncer de boca. O Grupo II apresentou redução em $50 \%$ do crescimento tumoral, o que foi associado à presença dos ésteres diterpênicos palmitato de caveol e de cafestol no grão de café verde. ${ }^{41}$

Os diterpenos apresentam ainda atividade anti-inflamatória por meio da inibição da produção de óxido nítrico e inibição de iNOS (sintetases do óxido nítrico induzido, responsáveis pela excesso de óxido nítrico em células inflamatórias, que podem ser a causa de lesões inflamatórias) ${ }^{42}$, do fator de transcrição nuclear NF-kappaB (responsável pela ativação de vários genes que corroboram com o processo inflamatório) e da inibição da ciclo-oxigenase-2 (COX-2, enzima que participa da conversão do ácido araquidônico em prostaglandinas, relacionada com angiogênese, desenvolvimento e progressão tumoral). ${ }^{43}$

Os diterpenos apresentam potencial antioxidante capaz de reagir com radicais livres (como o radical hidroxila) para proteger danos ao DNA. ${ }^{44-46}$

O mecanismo de ação do cafestol foi investigado sobre o nível de glutationa (GSH), em particular a via do gama-glutamilcisteína sintetase (GCS), enzima limitante da síntese da GSH. ${ }^{47} \mathrm{Em}$ animais, o consumo de café não filtrato com elevado teor da mistura de cafestol/caveol foi associado com a redução do risco de câncer de cólon e fígado. ${ }^{48}$ Outros trabalhos revelaram a redução da genotoxicidade provocada por agentes carcinogênicos como o 7,12dimetilbenz[a]antraceno (DMBA), aflatoxina $B_{1}\left(A_{F B}\right)$, benzo[a]pireno(B[a]P) e 2-amino-1metil-6-fenilimidazo[4,5-b]piridina (PhIP), associada à indução da glutationa-Stransferase e glucuronosil-S-transferase; o aumento na expressão de proteínas envolvidas na defesa antioxidante em células, como a $\gamma$-glutamil cisteína sintetase e heme oxigenase-1; e a inibição da expressão e/ou atividade do citocromo P450 envolvido na atividade carcinogênica. ${ }^{49-51}$

Os diterpenos têm o efeito negativo de aumentar a taxa do colesterol no organismo humano, através de alterações enzimáticas no fígado. ${ }^{52-55}$

No início da década de 1980, foi investigado o consumo de café por 14000 noruegueses, e concluiu-se que a ingestão acima de 9 xícaras por dia elevava o nível de colesterol numa taxa de $12 \%$ para homens e $11 \%$ para mulheres, em relação aos que ingeriam apenas uma xícara diária. ${ }^{53} \mathrm{~A}$ forma de preparo da bebida quente do café, como a produzida no café escandinavo, bem como o café expresso, o turco e o francês, que são bebidas não filtradas, tem um maior teor de diterpenos, enquanto este teor é negligenciável nos cafés coado e filtrado, usualmente praticados no Brasil. Em 1985, foi realizado um estudo com a ingestão de café fervido não filtrado e de café filtrado, inclusive com indivíduos hipercolesterolêmicos. A ingestão de café fervido durante 10 semanas levou ao aumento no colesterol, enquanto a ingestão de café filtrado neste mesmo período manteve constante o nível de colesterol. ${ }^{56} \mathrm{~A}$ correlação direta entre o maior teor dos diterpenos $\mathrm{x}$ elevação de colesterol foi descrita posteriormente em diversos estudos. ${ }^{57-59}$

\section{Métodos de extração do óleo e dos diterpenos a partir do grão de café cru}

A espécie botânica, a qualidade dos grãos, o tamanho da partícula após a moagem, o tempo de extração e o solvente influenciam o rendimento, o perfil e as propriedades do óleo de café. ${ }^{9,60}$ Durante o procedimento de extração devem-se prevenir a degradação térmica e oxidações em geral, os principais problemas quando se trata da qualidade do óleo de café. ${ }^{61,62}$ 
Vários métodos de extração de óleo são aplicados aos grãos de café cru, como será visto a seguir.

\subsection{Extração por prensagem}

A prensagem é uma prática antiga de extração de óleos, passando de prensas "primitivas" às prensas de parafuso, até chegar ao que hoje é usual para muitas indústrias: as prensas de parafuso contínuas e hidráulicas. ${ }^{63}$ Por não utilizar solvente, essa técnica preserva as propriedades naturais do óleo. No entanto, a eficiência na extração é menor que a extração por solvente, a menos que seja aplicada alta pressão, o que encarece o procedimento. ${ }^{64}$

A prensa mecânica consiste de um cesto formado de barras de aço retangular distanciadas, por meio de lâminas, com regulagem de espessura conforme a semente a ser prensada. $O$ espaçamento das barras é regulado de forma a permitir a saída do óleo e filtrar as partículas do resíduo de prensagem (torta). No centro do cesto gira uma rosca helicoidal que movimenta o material para frente, comprimindo-o ao mesmo tempo. A pressão é regulada por meio de um cone de saída, acionado por uma manivela. $\mathrm{O}$ acionamento do sistema é feito por um motor, seguido de um redutor. $O$ óleo bruto geralmente passa por um processo de filtração ou decantação para remoção do material mais fino (Figura 12). ${ }^{64}$

A extração por prensagem de óleo de grão de café cru apresenta rendimento cerca de $30 \%$ menor que o processo de extração por solvente químico. ${ }^{24,65}$

\subsection{Extrator Soxhlet}

O método por extração sólido-líquido, em extrator Soxhlet, é um dos mais relatados para café. ${ }^{66-72} \mathrm{O}$ método da Association of Official Analytical Chemists (AOAC, 1965) ) $^{73}$ sugere que os lipídeos sejam extraídos por repetidas lavagens com solvente orgânico (hexano ou éter de petróleo), em aquecimento sob refluxo. A amostra é colocada em filtro de celulose ou de papel, que é introduzido na câmara de extração, entre o condensador e o balão contendo o solvente. A base do balão é aquecida e logo o solvente começa a evaporar, condensando para gotejar no filtro que contém a amostra. Deve-se observar o número de ciclos de sifonagem para que haja reprodutibilidade a cada experimento. Esse processo de extração contínuo dura até 16 horas para o café. $\mathrm{Na}$ Figura 12 está ilustrado o extrator Soxhlet.

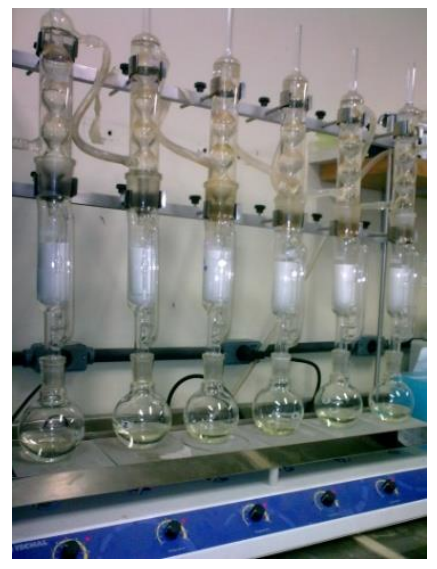

Figura 12. Extrator Soxhlet

As vantagens desse método estão no contato direto do solvente com o grão durante todo o período de extração, que resulta em maior quantidade de óleo em 
relação ao método de extração por prensagem (item 4.1.), além de não necessitar de etapa de filtração após a extração. ${ }^{61,74}$ No entanto, entre suas desvantagens estão o maior tempo de extração, grande consumo de solvente, favorecimento de peroxidação lipídica e a necessidade de etapa adicional de concentração. ${ }^{63,74}$
Apesar de ser oficializado pela AOAC (1965), ${ }^{73}$ o método tem diversas adaptações quanto ao tempo de extração e a natureza do solvente, como pode ser observado na Tabela $3 .^{75} 0$ método alemão de extração de lipídeos, por exemplo, publicado em 1952, trabalha com tempo de extração de 4 horas com éter de petróleo como solvente. ${ }^{9}$

Tabela 3. Comparação dos diferentes tempos de extração vs. rendimento utilizando extrator Soxhlet ${ }^{75}$

\begin{tabular}{|c|c|c|c|}
\hline Referência & $\begin{array}{l}\text { Solvente } \\
\text { utilizado }\end{array}$ & $\begin{array}{c}\text { Tempo de } \\
\text { extração (h) }\end{array}$ & $\begin{array}{c}\text { Rendimento de } \\
\text { extrato (\%) }\end{array}$ \\
\hline Pettitt, $1987 . .^{76}$ & éter de petróleo & 3 & $\mathrm{SI}$ \\
\hline Dibert e Cros, $1989 .{ }^{66}$ & hexano & 16 & 8,3 \\
\hline Carrera et al., $1998{ }^{67}$ & hexano & 8 & $12-20$ \\
\hline Lercker et al., 1995. ${ }^{77}$ & hexano & 8 & SI \\
\hline González et al., $2001 .^{68}$ & hexano & 8 & 15 \\
\hline Araújo e Sandi, $2006 .^{69}$ & hexano & 16 & 10,2 \\
\hline Ramalakshmi, Kubra e Rao, $2008 .^{71}$ & hexano & 8 & 8,4 \\
\hline Oliveira et al., 2008. ${ }^{70}$ & hexano & 16 & $10-12$ \\
\hline Scharnhop e Winterhalter, $2009 .^{39}$ & terc- butil metil éter & 5 & SI \\
\hline Oigman, 2012. ${ }^{75}$ & éter de petróleo & 4 & 7,0 \\
\hline
\end{tabular}

$\mathrm{SI} \rightarrow$ sem informação

\subsection{Incubadora orbital shaker}

A introdução do bioreator shaker em laboratório teve como objetivo o cultivo de micro-organismos em pequena escala e até hoje é utilizado em bioprocessos devido ao fácil manuseio, a possibilidade de números de experimentos paralelos e à fácil operação. ${ }^{78-80} \mathrm{O}$ método consiste no movimento orbital da bandeja e o suporte é fechado com controle de agitação e temperatura.

O frasco utilizado deve apresentar uma boa geometria, ou seja, o contorno e a distribuição espacial da massa de líquido em movimento de rotação no interior do recipiente são de grande importância. ${ }^{78} \mathrm{~A}$ agitação promove a homogeneidade do líquido com o material no interior do recipiente. $^{79}$

O método shaker tem sido pouco explorado para extração de óleo em grãos de

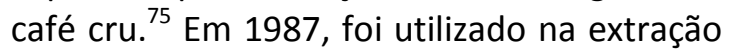
de diterpenos em café cru com acetonitrila, seguido de análise por cromatografia líquida de alta eficiência (CLAE). Foram obtidos seis ésteres diterpênicos: linoleato, palmitato, oleato, estearato e eicosanoato de caveol e somente um éster de cafestol, o palmitato. ${ }^{76}$ Em 2012, nosso grupo utilizou o shaker com o intuito de avaliar o seu desempenho para o 
rendimento em óleo, e obteve cerca de 7,8 \% de rendimento, semelhante ao alcançado com a extração em Soxhlet. ${ }^{75}$

\subsection{Extração com Fluido Supercrítico}

A partir do início da década de 1980, a extração por fluido supercrítico (EFS) foi proposta para a obtenção do óleo de café. ${ }^{99,81}$ A EFS é um método que emprega um fluido supercrítico como solvente extrator. ${ }^{82} \mathrm{O}$ procedimento consiste em depositar o material vegetal em um reservatório de aço inoxidável, sob pressão, adicionando-se geralmente $\mathrm{CO}_{2}$ em condições supercríticas $\left(31^{\circ} \mathrm{C}\right.$ e $\left.7,3 \mathrm{MPa}\right)$, onde o gás se torna liquefeito. Neste estágio, - $\mathrm{CO}_{2}$ possui viscosidade análoga a de um gás, porém com a capacidade de dissolução semelhante a um líquido, otimizando a extração. Posteriormente, $\mathrm{o} \mathrm{CO}_{2}$ retorna ao seu estado gasoso, resultando na obtenção de óleo isento de solvente. ${ }^{83,84}$

Este método utiliza baixa temperatura, minimizando a degradação térmica de substâncias lábeis. No entanto, o custo de aquisição do equipamento é oneroso. ${ }^{82}$ Alguns autores compararam a extração do óleo de café cru por EFS, com o método oficial da AOAC (1965) $)^{73}$ por Sohxlet em 16 horas $x$ EFS por 25 minutos. $O$ rendimento em óleo por EFS variou de 24 a $91 \%$ em óleo, enquanto na extração por Soxhlet foi obtido $11,3 \%$. No entanto, ao analisar os diterpenos por CLAE, o teor por EFS mostrou-se $50 \%$ inferior. ${ }^{69,73}$

\section{Métodos de quantificação dos diterpenos em óleo de café cru}

Os diterpenos do café são usualmente analisados por cromatografia líquida de alta eficiência com fase reversa (CLAE-FR) e detetor de UV, na forma livre (não esterificada), após reação de hidrólise básica em metanol (metanólise) ou por saponificação..$^{28,32,38,69,75,85}$ Glicerol e ácidos graxos metilados são subprodutos da metanólise, enquanto sais de ácidos graxos (ou ácidos graxos livres após acidificação) resultam da hidrólise. A etapa crítica para o isolamento dos alcoóis diterpênicos é a hidrólise. $O$ anel furano é lábil, sensível a ácidos e a oxidantes, passível de reações de adição, o que reforça a necessidade da implementação de técnicas de hidrólise mais seletivas. $^{28}$

A análise dos diterpenos livres é mais comumente realizada no óleo do café cru. Além dos estudos realizados também na bebida do café, há outros nos tecidos da semente, empregando a análise por CLAE após saponificação dos diterpenos. Os autores verificaram que cafestol e caveol se acumulam no endosperma e no perisperma, ao mesmo tempo e, assim como ocorre no metabolismo da sacarose, aparentemente estes diterpenos podem ser translocados entre os tecidos citados. ${ }^{85}$

Não há metodologia analítica padronizada para os diterpenos esterificados. Aspectos qualitativos foram investigados por cromatografia líquida acoplada a espectrometria de massa, acompanhado de investigação através de padrões previamente sintetizados. $^{32}$

Já foi relatado o uso da cromatografia de permeação em gel em Bio beads S-X3 para o isolamento dos diterpenos livres das espécies de café arábica e robusta, seguida da análise por CLAE. ${ }^{38} \mathrm{O}$ isolamento por CLAE em coluna semi-preparativa de fase reversa $\mathrm{C} 18$ e por cromatografia em contra corrente de alta velocidade (HSCCC) também encontra-se detalhado na literatura. ${ }^{39,68}$

Tentativas de utilização de cromatografia em fase gasosa mostraram que há degradação dos diterpenos, com formação de desidroditerpenos do cafestol e caveol, associados ao aquecimento no injetor do cromatógrafo. $^{86}$ A opção encontrada foi a derivatização com reagentes de silanização. ${ }^{54,76,87,88}$ 


\section{Considerações finais}

O óleo de café cru é rico nos diterpenos cauranos cafestol e caveol. Embora este óleo tenha aplicações industriais já estabelecidas, não há aproveitamento específico de seus diterpenos pela indústria. $\mathrm{O}$ número de publicações acerca dos diterpenos do café vem aumentando no Brasil nas últimas décadas, especialmente voltadas para novas técnicas de extração, análise do teor para fins de adulteração e controle de processo além de estudos de atividade biológica.

\section{Referências Bibliográficas}

${ }^{1}$ Abic, Associação brasileira da indústria de café, 2012. Disponível em <http://www.abic.com.br/publique/cgi/cgilu a.exe/sys/start.htm?sid=38>. Acesso em: 20 janeiro 2012.

${ }^{2}$ Martins, A. L.; História do Café, 1a. ed., Contexto: São Paulo, 2008.

${ }^{3}$ Grieg, M. D.; Café - Histórico, Negócios e Elite, 1a. ed., Olho D'água: São Paulo, 2006.

${ }^{4}$ Eccardi, F.; Sandalj, V.; O Café: ambientes e diversidades, 1a. ed., Casa da Palavra: Rio de Janeiro, 2004.

${ }^{5}$ Chou, T. M.; Benoxitz, N. L. Caffeine and coffee: effects on health and cardiovascular disease. Comparative Biochemistry and Physiology Part C: Pharmacology, Toxicology and Endocrinology 1994, 109c, 173. [CrossRef]

${ }^{6}$ Damodaran, S.; Parkin, K. L.; Fennema, O. R. Química de alimentos de Fennema, Artmed: Porto Alegre, 2010.

${ }^{7}$ Savian, A. L.; Varella, F. T.; Athayde, M. L.; Da Silva, C. B. Desenvolvimento e avaliação preliminar da estabilidade de emulsão nãoiônica O/A contendo óleo de café verde como potencializador de fator de proteção solar. Revista Brasileira de Farmacognosia 2011, 91, 82. [Link]

${ }^{8}$ Ballone, G. J.; Moura, E.; Cafeína, 2008. Disponível em: < http://www.psiqweb.med.br/site/?area=NO/
LerNoticia\&idNoticia=154>. Acesso em: 20 janeiro 2012.

${ }^{9}$ Speer, K.; Kölling-Speer, I. The lipid fraction of the coffee bean. Brazilian Journal of Plant Physiology 2006, 18, 201. [CrossRef]

${ }^{10}$ Charrier, A.; Berthaud, J. Em Coffee Botany, Biochemistry and Production of Beans and Beverage; Clifford, M. N.; Willson, K. C., eds.; Croom Helms: London e Sdyney, 1985, cap. 2.

${ }^{11}$ Souza, F. F.; Tese de Doutorado, Universidade Federal de Viçosa, Brasil, 2011. [Link]

${ }^{12}$ Batista Filho, A.; Anais da $X$ Reunião Itinerante de Fitossanidade do Instituto Biológico, Mococa, SP, Brasil, 2004.

${ }^{13}$ Dedecca, D. M. Anatomia e desenvolvimento ontogenético de Coffea arabica L. var. typica Cramer. Bragantia 1957, 16, 315. [CrossRef]

${ }^{14}$ Fagan, E. B.; Souza, C. H. E.; Pereira, N. M. B.; Machado, V. J. Efeito do tempo de formação do grão de café (Coffea sp) na qualidade da bebida = Effect of time on coffe bean (Coffea sp) grouth in cup quality. Bioscience Journal 2011, 27, 729. [Link]

${ }^{15}$ Clarke, R. J. Em Encyclopedia of Food Sciences and Nutrition; Caballero, B.; Trugo, L. C.; Finglas, P. M., eds.; Academic Press: Oxford: Reino Unido, 2003, 3, 1487. [CrossRef]

${ }^{16}$ Baggenstoss, J.; Poisson, L.; Kaegi, R.; Perren, R.; Escher, F. Roasting and Aroma Formation: Effect of Initial Moisture Content and Steam Treatment. Journal of Agricultural and Food Chemistry 2008, 56, 5847. [CrossRef]

${ }^{17}$ Moreira, D. P.; Tese de Doutorado, Universidade Federal do Rio de Janeiro, Brasil, 2009. [Link]

${ }^{18}$ Belitz, H. -D.; Grosch, W.; Schieberle, P.; Food Chem., 4a. ed., Springer: Berlin, 2009.

${ }^{19}$ Speer, K.; Kölling-Speer, I. Em Coffee Recent Developments; Clarke, R. J.; Vitzthum, O. G., eds.; Blackwell Science: Oxford, 2001, cap. 1 C.

${ }^{20}$ Alvarez, A. M. R.; Rodríguez, M. L. G. Lipids in pharmaceutical and cosmetic preparations. Grasas y Aceites 2000, 51, 74. [CrossRef] 
${ }^{21}$ Curi, R.; Pompéia, C.; Myasaka, C. K.; Procopio, J. Entendendo a gordura, Manole: Barueri, 2002.

22 Salisbury, F.; Ross, C. W. Plant physiology, Wadsworth: Belmont, California, 1992.

${ }^{23}$ Viani, R. Em Coffee physiology; Clarke, R. J.; Macrae, R., eds.; Elsevier Applied Science: London, New York, 1988, cap. 2.

${ }^{24}$ Wagemaker, T. A. L. Dissertação de Mestrado, Instituto Agronômico - Agricultura Tropical e Subtropical, 2009. [Link]

25 Nikolova-Damyanova, B.; Velikova, R.; Jham, G. N. Lipid classes, fatty acid composition and triacylglycerol molecular species in crude coffee beans harvested in Brazil. Food Research International 1998, 31, 479. [CrossRef]

${ }^{26}$ Vianni, R.; Braz-Filho, R. Ácidos Graxos Naturais: Importância e Ocorrência em Alimentos. Química Nova 1996, 19, 400. [Link]

27 Gutierrez, L. E. Composição em ácidos graxos de óleo de café: comparação de métodos de esterificação. Anais da Escola Superior de Agricultura Luiz de Queiroz 1976, 33, 79. [CrossRef]

${ }^{28}$ Oigman, S. S.; de Souza, R. O. M. A.; dos Santos Júnior, H. M.; Hovell, A. M. C.; Hamerski, L.; Rezende, C. M. Microwaveassisted methanolysis of green coffee oil. Food Chemistry 2012, 134, 999. [CrossRef]

29 Nackunstz, B.; Maier, H. G. Diterpenoide im Kaffee. Zeitschrift für LebensmittelUntersuchung und Forschung 1987, 184, 377. [CrossRef]

${ }^{30}$ Speer, K.; Montag, A. 16-O-Methylcafestol - ein neues Diterpen im Kaffee. Erste Ergebnisse: Gehalte in Roh- und Röstkaffees (16-O-Methylcafestol - a new diterpene in coffee. First results: contents in raw and roasted coffees). Deutsche LebensmittelRundschau 1989, 85, 381.

${ }^{31}$ de Roos, B.; Van der Weg, G.; Urgert, R.; Van de Bovenkamp, P.; Charrier, A.; Katan, M. B. Levels of Cafestol, Kahweol, and Related Diterpenoids in Wild Species of the Coffee Plant Coffea. Journal of Agricultural and Food Chemistry 1997, 45, 3065. [CrossRef]

32 Kurzrock, T.; Speer, K. Identification of kahweol fatty acid esters in Arabica coffee by means of LC/MS. Journal of Separation Science 2001, 24, 843. [CrossRef]

${ }^{33}$ Bengis, R. O.; Anderson, R. J. The Chemistry of the Coffee-Bean: I. Concerning the Unsaponifiable Matter of the Coffee-Bean Oil. Preparation and Properties of Kahweol. The Journal of Biological Chemistry 1932, 97, 99. [Link]

${ }^{34}$ Slotta, K. H.; Neisser, K. G. Zur Chemie des Kaffees, IV. Mitteil.: Zur Konstitutionsaufklärung des Cafesterols. Berichte der deutschen chemischen Gesellschaft (A and B Series) 1938, 71, 2342. [CrossRef]

${ }^{35}$ Wettstein, A.; Mischner, K. Zur Konstitution des Cafestols. (4. Mitteilung). Helvetica Chimica Acta 1943, 26, 788. [CrossRef]

${ }^{36}$ Corey, E. J.; Slomp, G.; Dev, S.; Tobinaga, S.; Glazier, E. R. Detection and Structural Analysis of Furans by Proton Magnetic Resonance. Journal of the American Chemical Society 1957, 80, 1204. [CrossRef]

${ }^{37}$ Finnegan, R. A.; Djerassi, C. Terpenoids. $X L V$. Further Studies on the Structure and Absolute Configuration of Cafestol. Journal of the American Chemical Society 1960, 82, 4342. [CrossRef]

${ }^{38}$ Kölling-Speer, I.; Strohschneider, S.; Speer, K. Determination of Free Diterpenes in Green and Roasted Coffees. Journal of High Resolution Chromatography 1999, 22, 43. [CrossRef]

${ }^{39}$ Scharnhop, H.; Winterhalter, P. Isolation of coffee diterpenes by means of high-speed countercurrent chromatography. Journal of Food Composition and Analysis 2009, 22, 233. [CrossRef]

${ }^{40}$ Lam, L. K. T.; Sparnins, V. L.; Watterberg, L. W. Isolation and Identification of Kahweol Palmitate and Cafestol Palmitate as Active Constituents of Green Coffee Beans That Enhance Glutathione S-Transferase Activity in the Mouse. Cancer Research 1982, 42, 1193. [Link]

${ }^{41}$ Miller, E. G.; Formby, W. A.; RiveraHidalgo, F.; Wright, J. M. Inhibition of hamster buccal pouch carcinogenesis by green coffee beans. Oral Surgery, Oral Medicine, Oral Pathology 1988, 65, 745. [CrossRef] 
${ }^{42}$ Kim, J. Y.; Jung, K. S.; Lee, K J.; Na, H. K.; Chun, H-K.; Kho, Y-H., Jeong, H. G. The coffee diterpene kahweol suppress the inducible nitric oxide synthase expression in macrophages. Cancer Letters 2004, 213, 147. [CrossRef]

${ }^{43}$ Kim, J. Y.; Jung, K. S.; Jeong, H. G. Suppressive effects of the kahweol and cafestol on cyclooxygenase-2 expression in macrophages. FEBS Lett. 2004, 569, 321. [CrossRef]

${ }^{44}$ Lee, K. J.; Jeong, H. G. Protective effects of kahweol and cafestol against hydrogen peroxide-induced oxidative stress and DNA damage. Toxicology Letters 2007, 173, 80. [CrossRef]

${ }^{45}$ Bertholet, R. United States Utility Patent 4,692,534 1987.

${ }^{46}$ IARC Monographs on the Evaluation of Carcinogenic Risks to Humans, 1991, 51, 41. [Link]

${ }^{47}$ Huber, W. W.; Scharf, G.; Rossmanith, W.; Prustomersky, S.; Grasl-Kraupp, B.; Peter, B.; Turesky,R. J.; Schulte-Hermann, R. The coffee components kahweol and cafestol induce $y$ glutamylcysteine synthetase, the rate limiting enzyme of chemoprotective glutathione synthesis, in several organs of the rat. Archives of Toxicology 2002, 75, 685. [Link]

${ }^{48}$ Huber, W. W.; Rossmanith, W.; Grusch, M.; Haslinger, E.; prustomersky, S.; PeterVorosmarty, B.; Parzefall, W.; Scharf, G.; Schulter-Hermann, R. Effects of coffee and its chemopreventive components kahweol and cafestol on cytochrome P450 and sulfotransferase in rat liver. Food and Chemical Toxicology 2008, 46, 1230. [CrossRef]

${ }^{49}$ Cavin, C.; Hodzhaeuser, D.; Scharf, G.; Constable, A.; Huber, W.W.; Schilter, B. Cafestol and kahweol, two coffee specific diterpenes with anticarcinogenic activity. Food and Chemical Toxicology 2002, 40, 1155. [CrossRef]

${ }^{50}$ Lima, F. A.; Sant'ana, A. E. G.; Ataíde, T. R.; de Omena, C. M. B.; Menezes, M. E. S.; Vasconcelos, S. M. L. Café e saúde humana: um enfoque nas substâncias presentes na bebida relacionadas às doenças cardiovasculares. Revista de Nutrição 2010, 23, 1063. [CrossRef]

${ }^{51}$ Cavin, C.; Marin-Kuan, M.; Langouët, S.; Bezençon, C.; Guignard, G.; Verguet, C.; Piguet, D.; Holzhäuser, D.; Cornaz, R.; Schilter, B. Induction of Nrf2-mediated cellular defenses and alteration of phase I activities as mechanisms of chemoprotective effects of coffee in the liver. Food and Chemical Toxicology 2008, 46, 1239. [CrossRef]

${ }^{52}$ Thelle, D. S.; Arnesen, E; Forde, O. H. The Troms $\varnothing$ heart study. Does coffee raise serum cholesterol? The New England Journal of Medicine 1983, 308, 1454. [CrossRef] [PubMed]

${ }^{53}$ Weusten-van der Wouw, M. P. M. E.; Katan, M. B.; Viani, R.; Huggett, A. C.; Liardon, R.; Lund-Larsen, P. G.; Thelle, D. S.; Ahola, I.; Aro, A.; Meyboom, S.; Beynen, A. C. Identity of the cholesterol-raising factor from boiled coffee and its effects on liver function enzymes. Journal of Lipid Research 1994, 35, 721. [Link]

${ }^{54}$ Urgert, R.; Van der Weg, G.; KosmeijerSchuil, T. G.; Van de Bovenkamp, R.; Hovenier, R.; Katan, M. B. Levels of the Cholesterol-Elevating Diterpenes Cafestol and Kahweol in Various Coffee Brews. Journal of Agricultural and Food Chemistry 1995, 43, 2167. [CrossRef]

${ }^{55}$ Hatzold, T. Em Introduction coffee; CHU, YF., eds.; John Wiley e Sons: New York, 2012. cap.1.

${ }^{56}$ Forde, O. H.; Knutsen S. F.; Arnesen, E; Thelle, D. S. The Troms $\varnothing$ heart study: coffee consumption and serum lipid concentrations in men with hypercholesterolaemia: an randomised intervention study. British Medical Journal 1985, 290, 893. [CrossRef] ${ }^{57}$ Gross, G.; Jaccaud, E.; Huggett, A. C. Analysis of the content of the diterpenes cafestol and kahweol in coffee brews. Food and Chemical Toxicology 1997, 35, 547. [CrossRef]

${ }^{58}$ Martín, M. J.; Pablos, F.; González, A. G. Discrimination between arabica and robusta green coffee varieties according to their chemical composition. Talanta 2001, 46, 1259.

[CrossRef] 
59 Kurzrock, T.; Speer, K. Em Proceedings Euro Food Chemistry. IX colloque, Amado, R.; Battaglia, R., eds., Sailer, Winterthur, 1997, 659.

60 Lago, R. B. do CEPPA 2001, 19, 319. [Link]

61 Brum, A. A. S.; De Arruda, L. F.; RegitanoD’arce, M. A. B. Métodos de extração e qualidade da fração lipídica de matériasprimas de origem vegetal e animal. Química Nova 2009, 32, 849. [CrossRef]

62 Dias, R. C. E. Tese de Doutorado, Universidade Estadual Londrina, 2009. [Link] ${ }^{63}{ }^{63}$ Oetterer, M.; Regitano-D'arce, M. A. B.; Spoto, M. H. F. Fundamentos de Ciência e Tecnologia de Alimentos, Manole: BarueriSão Paulo, 2006.

64 Moretto, E.; Fett, R.; Tecnologia de Óleos e Gorduras Vegetais na Indústria de Alimentos, 1a. ed., Varela: São Paulo, 1998.

${ }^{65}$ Turatti, J. M. Resumos da II Simpósio de Pesquisa dos Cafés do Brasil, Vitória, Espírito Santo, 2001.

66 Dibert, K.; Cros, E. Solvent extraction of oil and chlorogenic acid from green coffee part I: Equilibrium data. Journal of Food Engineering 1989, 10, 1. [CrossRef]

${ }^{67}$ Carrera, F.; León-Camacho, M.; Pablos, F.; González, A. G. Authentication of green coffee varieties according to their sterolic profile. Analytica Chimica Acta 1998, 370, 131. [CrossRef]

${ }^{68}$ González, A. G.; Pablo, S. M.; Martín, M. J.; León-Camacho, M.; Valdenebro, M. S. HPLC analysis of tocopherols and triglycerides in coffee and their use as authentication parameters. Food Chemistry 2001, 73, 93. [CrossRef]

${ }^{69}$ Araújo, J. M. A.; Sandi, D. Extraction of coffee diterpenes and coffee oil using supercritical carbon dioxide. Food Chemistry 2006, 101, 1087. [CrossRef]

70 Oliveira, L. S.; Franca, A. S.; Camargos, R. R. S.; Ferraz, V. P. Coffee oil as a potential feedstock for biodiesel production. Bioresource Technology 2008, 99, 3244. [CrossRef]

${ }^{71}$ Ramalakshmi, K.; Kubra, I. R.; Rao, L. J. M. Antioxidant potential of low-grade coffee beans. Food Research International 2008, 41, 96. [CrossRef]
72 Al-hamamre, Z.; Foerster, S.; Hartmann, F.; Kröger, M.; Kaltschmitt, M. Oil extracted from spent coffee grounds as a renewable source for fatty acid methyl ester manufacturing. Fuel 2012, 96, 70. [CrossRef]

${ }^{73}$ AOAC - Method 14.029. In: Official Methods of Analysis of the Association of Official Analytical Chemists Handbook, 10a. ed. edn. AOAC, Washington, DC, 1965.

74 Soxhlet, F. Soxhlet, über gewichtsanalytische Bestimmung des Milchfettes. Polytrchnisches Journal 1879, 232, 461. [Link]

${ }^{75}$ Oigman, S. S. Tese de Doutorado, Universidade Federal do Rio de Janeiro, Brasil, 2012. [Link]

${ }^{76}$ Pettitt Jr, B. C. Identification of the diterpene esters in Arabica and Canephora coffees. Journal of Agricultural and Food Chemistry 1987, 35, 549. [CrossRef]

77 Lercker, G.; Frega, N.; Bocci, F.; RodriguezEstrada, M. T. High resolution gas chromatographic determination of diterpenic alcohols and sterols in coffee lipids. Chromatographia 1995, 41, 29. [CrossRef]

${ }^{78}$ Freedman, D. Em Methods of Microbiology; Norris, J. R.; Ribbons, D. W., eds.; Academic Press: London and New York, 1970, cap.6.

${ }^{79}$ Büchs, J.; Maier, U.; Lorreter, S.; Peter, C. $P$. Calculating liquid distribution in shake flasks on rotary shakers at waterlike viscosities. Biochemical Engineering Journal 2007, 34, 200. [CrossRef]

${ }^{80}$ Lotter, S.; Büchs, J. Utilization of specific power input measurements for optimization of culture conditions in shaking flasks. Biochemical Engineering Journal 2004, 17, 195. [CrossRef]

${ }^{81}$ Sarrazin, C.; Le Quéré, J-L.; Gretsch, C.; Liardon, R. Representativeness of coffee aroma extracts: a comparison of different extraction methods. Food Chemistry 2000, 70, 99. [CrossRef]

82 Lanças, F. M. Extração com Fluido Supercrítico: Quo Vadis? Revista Analytica 2002, 2, 30. [Link]

${ }^{83}$ Ammann, A.; Hinz, D. C.; Addleman, R. S.; Wai, C. M.; Wenclawiak, B. W. Superheated water extraction, steam distillation and SFE of peppermint oil. Fresenius' Journal of 
Analytical Chemistry [CrossRef]

${ }^{84}$ Adio, A. M. Tese de Doutorado. Isolation and struture elucidation of sesquiterpenoids from the essencial oils of some liverworths (Hepaticae). University of Hamburg, Alemanha, 2005. [Link]

${ }^{85}$ Dias, R. C. E.; Campanha, F. G.; Vieira, L. G. E.; Ferreira, L. P.; Pot, D.; Marraccini, P.; Benassi, M. T. Evaluation of Kahweol and Cafestol in Coffee Tissues and Roasted Coffee by a New High-Performance Liquid Chromatography Methodology. Journal of Agricultural and Food Chemistry 2010, 58, 88. [CrossRef]

${ }^{86}$ Guerrero, G.; Suárer, M.; Moreno, G. Resumos da 20th International Colloquium on the Chemistry of Coffee, Bangalore, Índia, 2005.

${ }^{87}$ Ruiz del Castillo, M. L.; Herraiz, M.; Blanch, G. P. Rapid Analysis of Cholesterol-Elevating Compounds in Coffee Brews by Off-Line HighPerformance Liquid Chromatography/HighResolution Gas Chromatography. Journal of Agricultural and Food Chemistry 1999, 47, 1525. [CrossRef]

${ }^{88}$ Kamm, W.; Dionisi, F.; Fay, L-B.; Hischenhuber, C.; Schmarr, H-G.; Engel, K-H. Rapid and simultaneous analysis of 16-Omethylcafestol and sterols as markers for assessment of green coffee bean authenticity by on-line LC-GC. Journal of the American Oil Chemists' Society 2002, 79, 1109. [CrossRef] 